\title{
Decolonizing Stigma and Diagnosis as Healing Work
}

\author{
ELELWANI RAMUGONDO, PhD, Occupational Therapy Division, Department of Health and \\ Rehabilitation Sciences, University of Cape Town \\ REFILOE LEPERE, MA, Drama for Life, University of the Witwatersrand \\ WARREN NEBE, BADA, MA, RDT, Drama for Life, University of the Witwatersrand \\ Corresponding author: Elelwani Ramugondo \\ elelwani.ramugondo@uct.ac.za
}

\begin{abstract}
In order to disrupt dominant understandings of health and well-being, and to confront systemic injustices that result in ongoing health inequities, stigma must be addressed from both within and beyond the realm of medical diagnosis. The individualistic nature of diagnosis, that is characteristic of Western medical approaches, often perpetuates stigma. The role of diagnosis in biomedicine, as well as the historicity of professions and disciplines in Westernized health-care, intersect with different hierarchies of power, identities, and knowledges through mechanisms that operate across local and global contexts. This paper argues that a decolonial approach to health research, practice and education offers an important lens through which to critically analyse these intersections of power, identities, and knowledges. Such an approach can help disrupt dominant understandings of health and well-being. To advance the argument, examples of decolonial thinking approaches and pedagogical methods from South Africa are provided.
\end{abstract}

Keywords: Stigma; diagnosis; coloniality; decoloniality; Drama for Life; collective occupation; occupational consciousness

\section{Introduction}

This paper aims to advance three themes in arguing for a decolonial approach to health research, practice, and education. These themes are as follows: stigma must be addressed from both within and beyond the realm of diagnosis; the individualistic nature of diagnosis often perpetuates stigma; and the role of diagnosis in biomedicine, as well as the historicity of professions and disciplines in Westernized health-care, intersect with different hierarchies of power, identities, and knowledges. These themes are informed mostly by the current historical moment in post-1994 South Africa, where student activism has re-ignited the decolonization discourse, both locally and globally. The authors to this paper are academics at two universities that played a central role in protests during 2015 and 2016 in South Africa, under the \#RhodesMustFall and the \#FeesMustFall banners. These student-led protests, emerging from two historically white universities, University of Cape 
Town and University of the Witwatersrand, included a call for decolonized education and also highlighted mental health issues at these universities.

At the University of Cape Town, the high prevalence of suspected suicides among black students took centre-stage during student-led protests and continue to be a concern for many to date. Interestingly, even as there is general acceptance that institutional racism, and a sense of alienation and despair for a black student in a Westernized university (Grosfoguel, 2013) could be very wellfounded, the urge to pathologize and approach the issue at an individual level appears hard to resist. The University of Cape Town has yet to demonstrate its ability to secure meaningful and appropriate modalities for healing outside of the traditional Western approaches. This is in contrast to students at times bringing in the arts as part of disruptive spaces for protest during 2015-2016, or using the arts for their own individual and collective healing.

The dominant approach to mental health and well-being in Western medicine centres on diagnosis. This is also the approach generally adopted when Western-trained health professionals deal with other non-communicable diseases. There are implications for this approach in addressing stigma. A highly cited study on the epidemiology of major depression in South Africa was conducted during 2002-2004 (Tomlinson, Grimsrud, Stein, Williams \& Myer, 2009). Using a household survey based on the World Health Organization Composite International Diagnostic Interview, these researchers collected data from 4351 adult South Africans of all racial groups. The study found that $9.7 \%$ of the sample reported episodes of major depression over the life-time, while $4.9 \%$ reported these to have occurred during 12 months before the interview. The prevalence of depression was significantly higher among females than males. Depression was also higher among those with a low level of education, the research reported. Having compared these results with data from other countries, the researchers concluded that South Africa had lower rates of depression than the United States of America, but higher rates than Nigeria. 
What was interesting in the reporting of results from the study cited above was the silence about the prevalence of depression across race groups. On reading the report, one may be left wondering about the interplay between race, education levels, and depression prevalence in a country such as South Africa with its history of apartheid and continued patterns of inequality that still reflect past inequities. The report seems to underplay the importance of social determinants of health, which highlight the link between health and the economic and social conditions across different groups within a given population (WHO, 2006). Attention to social determinants of health casts the spotlight on unequal distribution of income, wealth, influence, and power across the population, rather than focus on individual risk factors, such as low levels of education in this case. Approaching stigma from both within and beyond the realm of diagnosis, as well as addressing the individualistic nature of diagnosis in health-care, can help advance the World Health Organization's call for action on social determinants of health.

Understanding intersections between gender, race, education level, socio-economic status, and depression level might inform advocacy efforts for particular re-distributions of mental health care services, and a careful exploration about what these services could entail. This is important, given that South Africa has yet to register any meaningful positive impact on health indicators for the majority of the population, even as there has been growth in the investment of resources spent on public health-care since 1994 (Mayosi \& Benatar, 2014). Major depression is often concomitant with other chronic illnesses such as HIV/AIDS and non-communicable diseases. In 2013, Statistics South Africa reported causes of death that are categorized as metabolic disorders (malnutrition and diabetes mellitus) and circulatory system diseases (hypertensive diseases, cerebrovascular diseases and heart diseases) to be at $6 \%$ and $17 \%$, respectfully (StatsSA, 2013).

Health service users often report that, usually, the focus from Western trained health practitioners is on the one who has been diagnosed, with little to no interaction with family members, or the community where the patient comes from. For mental illness and non- 
communicable diseases that are associated with genetic risk predisposition, such as diabetes mellitus, it appears that much can be achieved by engaging the whole family, not only as a way to demystify the condition and to raise awareness about prevention, but also to address stigma. A qualitative study conducted in Jamaica, for instance, found increased positive attitudes towards mental illness, when mental health services were integrated into the community (Hickling, Robertson-Hickling \& Paisley, 2011).

Communities that are witnessing increased levels of mental illness, as well as metabolic disorders and circulatory system diseases, have also seen huge lifestyle changes that have arisen through globalization and Western-led modernity. Disease patterns that spike in some communities more than others are an important pointer for analyzing inequalities that may still persist across society. These differences call for community-based approaches that facilitate and support efforts for analyzing the problem as contextually situated, rather than residing within the individual. These approaches should seek to foster self-determination and collective self-reliance. Such approaches are necessary if the new set of Sustainable Development Goals (SDGs) as endorsed by the United Nations General Assembly (United Nations, 2015) are to be achieved in countries such as South Africa. Sustainability of any of the 17 SDGs would be difficult to achieve if solutions must only be imposed on communities. Goal 17 in particular, calls for partnership. Partnership without recognizing agency within local communities for self-determination and collective reliance, otherwise rings false, if not cynical.

For conditions that are often associated with stigma, such as HIV/AIDS and mental health illness, a community approach that addresses stigma both within and beyond the realm of medical diagnosis is particularly critical. In their comprehensive examination of conceptual models of stigma and prejudice, Phelan, Link and Dovidio (2008) found that many of these models emphasized that human characteristics that are targeted - race, disease, and disabilities - are socially constructed. These authors also found that processes involved in targeting these characteristics varied 
significantly, depending on time and place. There is therefore a need to contextualise stigma, and to recognise that for mental health issues in particular, how a diagnosis is reached can aggravate or alleviate stigma. This paper's main argument is that in order to disrupt dominant understandings of health and well-being, and to confront systemic injustices that result in ongoing health inequities, stigma must be addressed from both within and beyond the realm of medical diagnosis.

This paper begins by tracing the roots of the notion of stigma from Greek etymology, in order to locate embedded intentions behind this construct, which may or might not have survived history. The role of diagnosis in biomedicine and how it intersects with different hierarchies of power, identities, and knowledges is then unpacked, contrasting this with the place for diagnosis in African healing traditions. This comparison, along with reflections on the meanings of coloniality, decolonization and decoloniality, lays the ground for making the case for a decolonial approach in health research, practice and education. Pedagogic case examples from Drama for Life, an international postgraduate programme based at the University of the Witwatersrand in South Africa but that spans across Africa and abroad, are offered as potentialities for decolonizing stigma and diagnosis, and advancing healing work.

\section{Stigma: Greek etymology and social function}

In Greek, stigma is a noun meaning mark, dot or sign (Lidell \& Scott, 1940). It is also a verb meaning to puncture. In its Greek form, the word stigma denotes marks on the skin made by tattooing. These marks are understood as the "mark of disgrace" (Lewis, 1891). The tattooing, using needles and ink, was done on those individuals who were to be punished. In an abstract written to frame discussion for a special session on the sociology of stigma at the British Sociological Association Conference in Manchester (April 4-6, 2017), Imogen Tyler makes salient points about the social function of stigma in post-war society (Tyler, 2017). The first point is around the permanency of stigma. The tattoo or stigma, as it was known, was a permanent marker. To be 
stigmatized was to have committed a wrong or crime, and this was recorded permanently upon one's skin. Unlike today perhaps, the tattoo embodied punishment.

The second point Tyler makes is about who this "mark of disgrace" (Lewis, 1891) was reserved for. This punishment was reserved for non-citizens, such as slaves, imprisoned enemy soldiers, or those regarded as aliens (Tyler, 2017). The third point is about what this permanent mark was meant to do. Tyler suggests that stigma served both a social and political function of shaming. Tyler concludes the abstract with an invitation for "a new conceptual vocabulary of stigma which emphasises stigma as a mechanism of coercion, a system of valuation, a communicative terrain and a form of power-knowledge. An account which allows for a focus on the mechanisms, the mechanics, of stigma production, activation and mediation - practices that I term 'stigmacraft"'.

Tyler's reflections on the function of stigma resonate very strongly with seminal work on stigma by Erving Goffman. In his classic theory of social stigma, Goffman (1963) transformed our understanding of stigma not just as an individual's problem, but also as a social function. Goffman offers a definition of stigma as "the situation of the individual who is disqualified from full social acceptance" (1963, preface).

Goffman identified three aspects of stigma that relate to the argument we wish to advance in this paper. Firstly, that those who are stigmatized are viewed as having blemishes to their personal character; they are not seen as people but rather as deviance personified. Secondly, Goffman notes that the stigmatized are judged as having a stained social identity and must therefore manage the shame of stigma by engaging in multiple strategies of passing and hiding. Thirdly, stigmatization functions "as a means of formal social control" (p. 139). Central to this idea is that stigma is a form of power that reproduces the economic and social inequalities of class, race, and gender (Parker \& Aggleton, 2003). The poor and the marginalized are therefore more likely to be stigmatized than privileged individuals. 
Goffman's perspective on the social function of stigma has survived time. From their analysis of conceptual models of stigma and prejudice, Phelan, Link and Dovidio (2008) describe a typology of three social functions of stigma and prejudice: exploitation and domination, norm enforcement, and disease avoidance. Through this analysis, the consequences to those who are targeted through stigma and prejudice, become vivid, just as Goffman's classic theory also exposes. Those who are targeted are kept down, made to conform, whilst at the same time kept away (Phelan, Link \& Dovidio, 2008).

Within health-care, stigma that is associated with illness is regarded as a major health concern (Muijen, 2006; Sartorius, 2004; Stuart, 2008 \& WHO, 2001), with some similar trends across high-income and low-income countries (Mascayano, Tapia, Schilling, Alvarado, Tapia, Lips \& Yang, 2016). Differences in expressions of stigma in Latin America and the Caribbean have been associated with Latin American culture, which is rooted in strong family and community networks, but has also been found to be generally patriarchal (Mascayano et al., 2016).

It is not enough to say that a disease causes stigma for an individual, when in reality it is people who stigmatize other people, following a diagnosis. In this paper, we emphasize that our interest as health practitioners should lie in the dynamic that is created when hierarchies of power, identities, and knowledges intersect in ways that produce unequal access to health and well-being. The definition of stigma is inextricably linked to power relations and structures. Stigma therefore, strongly tracks along social inequality lines. A decolonial approach to addressing stigma may thus be important to our work as theatre makers, applied drama facilitators, drama therapists, occupational therapists, and health professionals in general.

\section{Diagnosis: Power, identities and knowledges as sites for decolonial work}

Diagnosis, as both a process and an outcome of investigation, plays a critical role in modern health-care. It allows access to appropriate health professionals, and in some cases, it is critical in 
enabling resistance to stigmatization (Farrugia, 2009). Yet, in the process of diagnosing, it is always the body that is assumed or found to have a problem. In this way, through diagnosis, stigma, as something marked on the body, finds historical coherence with its Greek etymology.

The process of diagnosis in biomedicine saliently maps out the power differential between the doctor and the patient. On the one hand, immense power is afforded the doctor who is deemed to hold the necessary skills to locate the problem in the body, and to fix it. On the other hand, the patient is rarely believed to know what could be wrong, both within and outside the body. This dialectic of power, characteristic of the doctor-patient relationship within much of Western medicine extends into the broader therapeutic milieu and is reinforced both structurally and through the different roles played by members of the multi-disciplinary team.

The relationship between the healer and the patient in other traditions of healing often starts and unfolds in ways that do not inscribe strict linear dynamics of power that are usually seen in biomedicine where the doctors, as the expert knowers, can feel that they hold life and death in their hands. Participatory approaches to health-care in Westernized medicine also embrace the idea of the individual seeking help as an essential part of the healing process, and acknowledge the complementary roles the doctor and the patient play in the healing relationship.

In non-Western traditions of healing, a diagnosis often does not fall on the individual patient alone to bear. In African healing traditions, it is the case that the would-be healer may even be afflicted with 'the problem' borne by a patient before the patient even arrives for consultation (de Andrade \& Ross, 2005). The African traditional healer is often visited by dreams that point them to a cure (de Andrade \& Ross, 2005 \& Umsamo Institute, 2016), often selected for that particular patient, and for that particular time such as a root, a plant or piece of earth (Omonzejele, 2008 \& Truter, 2007). Consultation as a form of diagnosis often involves communication with ancestors (Truter, 2007), and is dependent on the afflicted agreeing with the messages being transmitted through the healer, as the medium. For instance, "Si ya vuma!" is an Nguni refrain that means "We agree!" (de 
Andrade \& Ross, 2005), and is used in most if not all African healing traditions in South Africa. The plural nature of the refrain suggests that the patient is never seen as an individual who comes alone for consultation (Truter, 2007), even if they may be one body in the physical form, in the room. "Si ya vuma!" as a refrain is required during the consultation process where ancestors are consulted to allow for the diagnosis to be made (de Andrade \& Ross, 2005).

In African healing traditions the power to cure is believed to reside with ancestors, with the healer serving only as medium, and the affliction often seen as an invitation or reminder for those afflicted to seek reconciliation with their ancestors (Iroegbu, 2005; Magesa, 1997; Mbiti, 1990 \& Nyamiti, 1984). Diagnosis, in this case, often points to relationships that need healing even beyond the grave (Magesa, 1997 \& Nyamiti, 1984). Illness for the patient may also at times serve as an invitation for them to become a healer themselves (Mokgobi, 2014 \& Umsamo Institute, 2011). This is not to suggest that patient-healer relationships and power dynamics in African healing traditions are never problematic. There are many instances where the role of medium is abused by "healers" and used for purposes other than healing, such as wealth accumulation and dealing with those who are seen as enemies in the living world (Truter, 2007).

The exploration of stigma as a social function and a form of power that reproduces economic and social inequalities, as well as the need to treat diagnosis in ways that situate the individual in their socio-historical context: where traditional healing practices that are experienced as helpful can be taken into consideration, requires a decolonial approach to health research, practice and education. This approach necessitates some reflection on the meanings of coloniality, decolonization, and decoloniality in relation to power, knowledges, and identity or being.

\section{Coloniality, decolonization and decoloniality: Power, knowledges and being}

The structural elements that intersect with the therapeutic milieu are historically situated both locally and globally. Coloniality, which refers to the pervasive Western-led mode of civilization and 
modernity that has continued beyond colonization, and that has sustained racism as an on-going organizing principle that structures all of the multiple hierarchies of the world system (Grosfoguel, 2011), can therefore, not be ignored.

Coloniality must be recognized in order to understand how power operates within Westernized health-care and to confront systemic injustices that result in ongoing health inequities. Decolonization and decoloniality are modes of resistance that date back to the very beginning of colonisation, and continue today wherever people face continued racial oppression and associated systemic injustices. It is not surprising therefore, that student leaders of the \#RhodesMustFall and \#FeesMustFall campaigns tapped into the decolonial register to articulate their struggle against institutional racism and inaccessible higher education, and to illustrate how these relate to high levels of suspected suicides amongst black students at one historically white university in South Africa.

As concepts, decolonization and decoloniality are used widely by a range of social justice activists, scholars, and artists in the Global South, which includes the Americas, Africa, Asia, and parts of Europe (Maldonaldo-Torres, 2016). Decolonization is a term that is used to describe the physical withdrawal of colonial administrators from the colonies, as well as the struggles waged against those empires that were unwilling to withdraw voluntarily (Ndlovu-Gatsheni, 2013). Decoloniality on the other hand, emphasizes coloniality, while acknowledging that colonization was a historical phenomenon that was countered by liberation struggles across many parts of the world (Grosfoguel, 2011).

Ndlovu-Gatsheni (2015) refers to decoloniality as a long-standing political and epistemological movement that is aimed at the "liberation of (ex)-colonised people from global coloniality" (p. 485). Ndlovu-Gatsheni (2013) delineates the notion of decoloniality along three concepts: coloniality of power, coloniality of knowledge, and coloniality of being. 
Coloniality of power highlights the asymmetrical matrix of power that persists beyond the withdrawal of colonial administrators from the colonies, and results in unequal nation states that are different along historical imperial and non-imperial lines. This concept reveals the extent to which colonization laid the foundation for the continuous subjugation of (ex)-colonised people, and how decoloniality requires the realignment of power between nation states, such that self-determination and collective self-reliance can be lived locally, and felt globally for all, and not just in the Global North.

Coloniality of knowledge describes the ways in which endogenous, indigenous or traditional knowledges from non-Western worlds have often been demonized or presented as inferior, while at the same time appropriated to serve imperial powers and to claim white supremacy. This concept highlights the importance of looking at the historicity of professions and disciplines. There may be noble reasons why a particular profession or discipline exists or was conceived of in the first place. However, when one begins to historicize professions or disciplines, one may encounter baggage that a profession or discipline inherited when transplanted from one part of the world to another, or problems introduced by bowing too far towards interests beyond those pertaining to human, animal and plant life.

Westernized universities (Grosfoguel, 2013), wherever they are located globally, have often inherited disciplines as they were conceived and constructed in North America and Europe. White males from Germany, France, England, Italy, and the United States of America took a central role in driving their own conception of the world, even beyond their own limited geographical locations (Grosfoguel, 2013). This construction of knowledge necessitated a particular treatment of the knowledge project as universal, and its origins as only possible from select parts of Europe or North America. In this manner, Africa and other (ex)-colonized parts of the globe were deemed as having nothing to teach the rest of the world. 
The construction of knowledge as only possible from some parts of the world (Europe and North America), and not others (Africa for example), renders as invisible, or reduces as inferior, those human "beings" that reside in these "othered" worlds. Decoloniality of being, therefore, entails reclaiming a sense of full humanness by the (ex)-colonized people, in ways that recognize endogenous, indigenous or traditional knowledges as worthy contributions to our global intellectual heritage.

Diagnosis, the form it takes in western medicine, who benefits or suffers through the process, and the long term implications that arise for disciplines, professionals and their professions, as well as whole communities, needs to be approached with the intention to decolonize power, identity and knowledge, and to trouble unequal and historically inscribed subjectivities of difference.

\section{Decolonizing health research, practice and education}

In order to address the coloniality of power, knowledge, and identity or being, it is imperative that decoloniality addresses research, practice, and curricula. Westernized universities are often more comfortable in addressing lack of diversity in student and staff profiles, and sometimes even institutional symbolism, as a way to foster inclusion.

Curricula are harder to decolonize, as there is much vested interest in colonial canons of thought and content as well as pedagogic practices for epistemically obedient members who may have both wittingly or unwittingly advanced colonial interests (Mignolo, 2009). Even as a decolonial framework opens up, rather than closes, possibilities for the expansion of the knowledge project, there is often anxiety about new-found inadequacies when knowledge formerly deemed to be of less value is found to reside more with (ex)-colonized people as experts. There may also be understandable fear of potential retribution, when instances of genocide/epistemicide with the participation of disciplines are exposed (Grosfoguel, 2013 \& Ndovu-Gatsheni, 2013). 
Decolonizing research is even harder because Westernized universities are often at best, (1) instrumentalist in that they pre-occupy themselves with announcing and fixing surface problems without first attending to why these problems exists, and (2) opportunistic in that they mostly prioritize funded research with funders often driving the research agenda. In order to confront systemic injustices that result in ongoing health inequities, a decolonial approach to health-care must address research, education, and practice simultaneously.

\section{A decolonial classroom approach - building theory through practice}

In an attempt to provide a democratic learning experience, Drama for Life has a unique course where the Master of Arts in the field of applied drama, 'Theatre in education, communities and social contexts', and the Master of Arts in the field of drama therapy come together in a central course called, 'Critical reflexive praxis'. The class, which was historically taught by Warren Nebe and currently by Refiloe Lepere, explores the interdisciplinary intersections between drama, theatre, performance and sociological implications of change. In the course, theory and practice of education are interrogated, through the use of drama, theatre, and performance, with a view of developing a unique, community-based praxis. The course challenges students to approach their work in a reflective and reflexive manner and provides an opportunity for students to learn about their context, self, and others.

The core lecture material is framed around the concept of dramaturgy, which promotes critical thinking and prompts students to conceive of life from a sociological perspective. Dramaturgy contends that individual and collective action are both political and symbolic. The role that power plays in intersecting systems is critically analyzed, in ways that are not limited to race, class, and gender, but also sexuality, citizenship, and ability. This course attempts to embrace the continuum of arts-based activism, education, development, and therapy. The goal of the course is to 
provide the basis on which students can build tools to become applied drama and drama therapy practitioners.

In creating the seminars, students together with the lecturer, are required to examine practice and how actions can generate or are generating theory and research questions. The central question is how might we "practice" in more thoughtful ways and "theorize" in more relevant ways.

The course and classes are framed in ways that look at dynamics of power and powerlessness. Class engagements allow for questions about the relationship between ourselves and other, and how influences of culture, race, ethnicity, and belief or worldview sit in the room. Selfinterrogation centres on how one sees the world, and what assumptions come forth in interactions with other participants or health service users. Whatever is taken for granted, the impact thereof, and our responsibility for constructing life, the self and the social, is interrogated (Cunliffe, 2009). The class also delves into African notions of wellness, health, and disease, and work that has been pivotal to participants' own thinking about practical plans to combat social stigma. Indeed, what distinguishes Drama for Life class processes from existing research on stigma is this explicit focus on stigma and power, and on stigmatization as a central dimension of crafting power relations.

These examples from Drama for Life intersect strongly with theorizing work informed by discourse on the politics of human occupation from South Africa, as part of the Global South, in occupational science, a discipline born out of occupational therapy. People's individual-collective culpability or complicity, in relation to actions that sustain oppression or disrupt dominant practices that marginalize, is explained through Ramugondo and Kronenberg's (2015) definition of collective occupation: an occupational science construct. These authors framed their explanatory approach for collective occupation around the concept of Ubuntu. This concept is defined by Cornell and Van Marle (2005), citing Mudimbe, a Congolese Philosopher, as referring to an ontic ethic and an ongoing process through which we become human, with the individual and the collective carrying the responsibility to humanize each other rather than being in competition. Collective occupations 
thus refer to those acts "that are engaged in by individuals, groups, communities and/or societies in everyday contexts [that] may reflect an intention towards social cohesion or dysfunction, and/or advancement of or aversion to a common good" (Ramugondo \& Kronenberg, p. 10). The authors further propose that "these collective occupations may have consequences that benefit some populations and not others" (p. 10). Based on this understanding, Ramugondo and Kronenberg (2015) argue that people's shared humanity is constantly being shaped by what they are able to do or unable to do within groups, communities, and society.

Another occupational science construct, emerging from research and practice in South Africa, as part of the theorizing work informed by discourse on the politics of human occupation, and grounded on the liberation philosophy as espoused by Stephen Bantu Biko, Enrique Dussel, and Frantz Fanon, is occupational consciousness (Ramugondo, 2015). This construct is concerned with how everyday doing can reflect unwitting consent on the part of the oppressed to the ways in which global dominant cultural practices assert and embed themselves within local contexts, often with consequences for individual and collective health. Occupational consciousness, as a decolonial thinking tool for resistance and self-advocacy, calls for individuals within marginalized communities to pay attention to their spaces of occupational influence and how their everyday doings can begin to disrupt societal dynamics of dominance. The class-room is a powerful space of occupational influence to interrogate theory and the practice of education, and carries with it potentialities for decolonial research and health-care practice. Significantly, the class-room can be an important space within which to build empathy on the basis of understanding the significance of the socio-historical context that surrounds the individual seeking healing as well as their choices, awareness of structural/systemic forces, and the dynamic relationships between stigma, diagnosis and healing practices that influence and impact their life stories. 


\section{Storytelling as counter-narrating and theory building}

The class as a space of occupational influence involves creating an environment in which students can commune in a discovery of various ways that our modern-day trauma plays itself out. Ways in which differing histories, memories, and unequal proximities to an ever-changing world, intersect. Classes in the Critical Reflexive Praxis Course in Drama for Life are structured by storytelling and role-playing activities that strive for an honest representation of shame, race, culture, self, and the human condition. Students engage in robust dialogue and conversations on the construction of race, diagnoses, and social inequalities. Unlike a typical didactic theoretical class, here there is personal storytelling that ensues during each class, which pushes each seminar into addressing issues raised in previous engagements. In these classes there is a sense of collective creation, therefore enhancing the experiences that are brought into the room, which needed to be shared.

It is in the storytelling processes that one is able to re-construct identities, answer questions about who one is and what one believes. Drama and artistic expression serve many functions in social and political contexts, but in these classes, it is mostly aimed at producing knowledge and solidarity within the group of creators and others/audiences. This expression can also be viewed as a means of communicating. This storytelling encounter is a form of counter-storytelling. Solorzano and Yosso (2002) define counter-storytelling as "a method of telling the stories of those people whose experiences are not often told" (p. 26). Counter-storytelling assumes that there are stories that are often told; these stories are deemed the dominant narrative (Solorzano \& Yosso, 2002). It is therefore important to have counter narratives that expose, analyze, as well as challenge deeply entrenched characterizations of race, gender, and privilege (Solorzano \& Yosso, 2002).

In a sense, counter-stories promote "human stories" (McQuail, 2010). The narratives put a human face to the experiences of the oppressed and marginalized people in any context and any 
society. Counter-stories are not always in direct response to the dominant stories. The sharing of insights or experiences of someone outside of the dominant culture can be sufficient in itself to create a counter-narrative (Williams, 2004).

Students are also required to participate in specific social action initiatives. These can vary from facilitating dialogues, to being part of a protest (a form of collective occupation) or writing a blog, social media post, or op-ed column on a social issue. For each social action, students present what ensues in class and then write a reflection essay. The presentation and essays provide both an assessment of the action and of the student's own self-evaluation of learning, as well as the student's theoretical and ethical understanding of what is meant by social justice. By using personal stories, metaphors, videos, and photographs, students are able to create their own counter-narratives that interpret their work in the community. The use of social media reveals very personal stories that would have otherwise been missed by traditional theory and practice, therefore making a case for personal revolutionary work in the classroom. Through these social media platforms, students are able to disseminate their own stories, words, and images to each other, and, most importantly, to the outside world (Lepere, Godsell, Mafoko \& Nase, 2016). The premise of the class is that stories are key in how we shape our lives. It is through stories that meanings are made. The narratives we hear and read shape and mould our experiences into who we become. There is something significant about telling a story, which makes people want to tell it and share it over and over in many different ways. Social media offers this telling and retelling option.

\section{Decolonial workshops and performances: Hearing voices}

The workshops and the play, Heading Out, explores the life of a voice-hearer who confronts her voice. The play tells the story of how one woman takes the time to finally face her fears, trauma, and voices. The workshops were birthed out of a series of therapeutic theatre work. Through an experiential process, the facilitator seeks to show how embodiment and the use of theatre methods 
can illuminate the complex experience of hearing voices. In an exploration of self through theatre, the workshops disclose how underlying tensions and indirect prejudice related to hearing voices are perceived and performed. The play presents an honest representation of shame, race, culture, self, mental illness, and the human condition. It is a personal reflection on how the composition and performance can help us understand mental illness. The play explores the question of what really goes on inside the conversation between a voice and a hearer. It explores the life of a voice hearer with the ultimate goal of trying to find some normalcy to their everyday life.

The workshops were inspired by the fact that hearing voices is a much-stigmatized experience. As educators and facilitators, we wanted to create a safe place where participants could find out more about hearing voices and form an interactive community where they can hear different points of view about the experience. The workshop explores ways of overcoming the difficulties faced by people who hear voices, as well as the more positive aspects of the experience and its cultural and historical significance. It also offers a very different way of thinking about the meaning of hearing voices. As a voice hearer one gets to express the views of understanding that the "voices" are real and can be meaningful, and are something that is experienced by some people, including many who have no problems living with their voices.

The workshops aim to add to the professional practice and insight that hearing voices is more like a variation in human behaviour, which does not have to be traumatizing or stigmatized, that it can be like being left-handed, and that it is not so much the voices that are the problem, but the difficulties that some people have in coping with them.

\section{Conclusion}

The freedom to be different without being locked into marginalized existence is an expression of our full shared humanity. While diagnosis serves an important purpose in health-care and ensures access to appropriate professional care, it often intersects with different expressions of 
coloniality and can aggravate stigma for marginalized and oppressed people. When stigma is addressed both within and beyond the realm of medical diagnosis, and in ways that allow for a decolonial approach to health practice, research, and education, possibilities arise for re-imagined subjectivities of difference that resist a re-inscription of colonial unequal relations of power. Hearing voices, for example, becomes less one-dimensional but more fluid, allowing for different possibilities of healing.

\section{References}

Cornell, D. H. \& Van Marle, K. (2005). Exploring Ubuntu: Tentative reflections. African Human Rights Law Journal, 5(2), 195-220.

Cunliffe, A.R. (2009). The philosopher leader: On relationalism, ethics and reflexivity-A critical perspective to teaching leadership. Management Learning, 40 (1), 87-101. doi: $10.1177 / 1350507608099315$

Davids, N. \& Waghid, Y. (2016, October 9). History of South African student protests reflects inequality's grip. The Conversation. Retrieved from http://theconversation.com/history-ofsouth-african-student-protests-reflects-inequalitys-grip-66279

de Adrande, V. \& Ross, E. (2005). Beliefs and practices of Black South African traditional healers regarding hearing impairment. International Journal of Audiology, 44, 489 - 499.

Eybers, C. (2015). How did we get here? A brief timeline that looks at the start and spread of the student protests throughout the country [Video file]. Retrieved from http://ewn.co.za/Features/year-of-the-student\#/03

Farrugia, D. (2009). Exploring stigma: medical knowledge and the stigmatisation of parents of children diagnosed with autism spectrum disorder. Sociology of Health \& Illness, 31(7), 1011-1027. doi: 10.1111/j.1467-9566.2009.01174.x

Goffman E. (1963). Stigma: Notes on the management of spoiled identity. Englewood Cliffs, NJ: Prentice-Hall, Inc. 
Grosfoguel, R. (2011). Decolonizing post-colonial studies and paradigms of political-economy: Transmodernity, decolonial thinking, and global coloniality. Transmodernity: Journal of Peripheral Cultural Production of the Luso-Hispanic World, 1(1), 1-38.

Grosfoguel, R. (2013). The structure of knowledge in Westernized universities: Epistemic racism/sexism and the four genocides/epistemicides of the long 16th Century. Human Architecture: Journal of the Sociology of Self-Knowledge, 11(1), 73-90. Retrieved from http://scholarworks.umb.edu/humanarchitecture/vol11/iss 1/8

Hickling, F. W., Robertson-Hickling, H., \& Paisley, V. (2011) Deinstitutionalization and attitudes toward mental illness in Jamaica: a qualitative study. Revista Panamericana Salud Pública, 29,169-76.

Iroegbu, P. (2005). Healing insanity: Skills and expert knowledge of Igbo healers. African Development, 30(3), 78-92. http://dx.doi.org/10.4314/ad.v30i3.22231

Lewis, C. T. (1891). An elementary Latin Dictionary. Cincinnati, NY: American Book Company. Lepere, R. Godsell, G. Mafoko S. and Nase, A (2016) Documenting the revolution. In S. Booysen (Ed.), Fees Must Fall: Student revolt, decolonisation and governance in South Africa (pp. 54-73). Johannesburg, South Africa: Wits University Press.

Lidell, H. G. \& Scott, R. (1940). A Greek-English Lexicon. Oxford, England: Clarendon Press. Magesa, L. (1997). African religion: The moral traditions of abundant life. Maryknoll, NY: Orbis Books.

Maldonaldo-Torres, N. (2016). Outline of ten theses on coloniality and decoloniality. Retrieved from http://frantzfanonfoundation-fondationfrantzfanon.com/IMG/pdf/maldonadotorres_outline_of_ten_theses-10.23.16_.pdf

Mayosi, B. M. \& Benatar S. R. (2014). Health and health care in South Africa-20 years after Mandela. The New England Journal of Medicine, 371, 1344-1353. doi: 10.1056/NEJMsr1405012 
Mbiti, J. S. (1990). African religions and philosophy. London, England: Heinemann.

McQuail, D. (2000) McQuail’s mass communication theory. London, England: Sage

Mignolo, W. D. (2009). Epistemic disobedience, independent thought and de-colonial freedom. Theory, Culture \& Society, 26(7-8), 1-23. doi: 10.1177/0263276409349275

Mokgobi, M. G. (2014). Understanding traditional healing. African Journal for Physical Health Education, Recreation \& Dance, 20 (Suppl. 2), 24-34.

Muijen, M. (2006). Challenges for psychiatry: delivering the Mental Health Declaration for Europe. World Psychiatry, 5(2), 113-117.

Ndlovu-Gatsheni, S. J. (2013, February). Why Decoloniality in the 21st Century? The Thinker, 48, $10-15$.

Ndlovu-Gatsheni, S. J. (2015). Decoloniality as the future of Africa. History Compass, 13(10), 485496. doi:10.1111/hic3.12264

Nyamiti, C. (1984). Christ as our ancestor: Christology from an African perspective. Gweru, Zimbabwe: Mambo Press.

Omonzejele, P.F. (2008). African concepts of health, disease, and treatment: An ethical inquiry, Explore, 4(2), 120-123. http://dx.doi.org/10.1016/j.explore.2007.12.001

Parker R. \& Aggleton P. (2003). HIV and AIDS-related stigma and discrimination: A conceptual framework and implications for action. Social Science \& Medicine, 57(1), 13 - 24.

Phelan, J., Link, B. G. \& Dovidio, J. F. (2008). “Stigma and prejudice: One animal or two?” Social Science Medicine, 67(3): 358-367. doi:10.1016/j.socscimed.2008.03.022.

Ramugondo, E. L. (2015). Occupational consciousness. Journal of Occupational Science, 22(4), 488-501. doi:10.1080/14427591.2015.1042516

Ramugondo, E. L., \& Kronenberg, F. (2015). Explaining collective occupations from a human relations perspective: Bridging the individual collective dichotomy. Journal of Occupational Science, 22(1), 3-16. doi:10.1080/14427591. 2013.781920 
Sartorius, N. (2004). The World Psychiatric Association global programme against stigma and discrimination because of stigma. In A. H. Crisp (Ed.) (Rev. ed.). Every family in the land (pp. 373-375). London, England: Royal Society of Medicine Press.

Solorzano, D. G., \& Yosso, T. J. (2002). Critical race methodology: Counter-storytelling as an analytical framework for education research. Qualitative Inquiry, 8(1), 23-44.

StatsSA (2013). Causes of Death 2013. Retrieved from http://www.statssa.gov.za/?page_id=737\&id=3

Stuart, H. (2008). Fighting the stigma caused by mental disorders: past perspectives, present activities, and future directions. World Psychiatry, 7(3),185-188.

Tomlinson, M., Grimsrud A. T., Stein D. J., Williams, D. R., \& Myer, L. (2009). The epidemiology of major depression in South Africa: results from the South African stress and health study. South African Medical Journal, $99(5$ Pt 2), 367-373.

Truter, I. (2007). African traditional healers: Cultural and religious beliefs intertwined in a holistic way. South African Pharmaceutical Journal, 60, 56-60.

Tyler, I. (2017). An abstract: Introduction to the special session: Stigmacraft. Retrieved from https://thestigmadoctrine.wordpress.com/2017/03/14/the-sociology-of-stigma-a-specialsession-at-the-british-sociological-association-conference-in-manchester-april-4-6-2017/

Umsamo Institute (2011). Ukuthwasa. Retrieved from http://umsamo.org.za/wpp/ukuthwasa/ Umsamo Institute (2017). Contextual family healing (therapy). Retrieved from http://umsamo.org.za/wpp/contextual-family-healing-therapy/

United Nations (2015). Transforming our world: The 2030 agenda for sustainable development. Retrieved from https://www.un.org/pga/wpcontent/uploads/sites/3/2015/08/120815_outcome-document-of-Summit-for-adoption-of-thepost-2015-development-agenda.pdf 
Williams, B. T. (2004). The truth in the tale: Race and "counterstorytelling" in the classroom. Journal of Adolescent \& Adult Literacy, 48(2), 164-169.

World Health Organization (WHO) (2001). The world health report 2001 - Mental health: new understanding, new hope. Geneva.

World Health Organization (WHO) (2006). Commission on social determinants of health. Geneva. 